\title{
Potential effects of climate change on U.S. forests: a review
}

\author{
Steven M. Winnett* \\ U.S. Environmental Protection A gency, O ffice of Ecosystem Protection, Boston, M assachusetts 02203, USA
}

\begin{abstract}
Human-induced changes in climate are likely to affect U.S. domestic forests and the economic systems which rely on them. This paper reviews current knowledge of how changes in temperature and precipitation could affect tree species, forest ecosystems, and the forest products sector of the economy. The various types of models used to predict change and the results they calculate are examined. M odels currently project both increases and decreases in the range of various species and ecosystems, and similar results for changes in the productivity, biomass and growth of forests in response to changes in climate. Results vary with the models used, the species or ecosystem studied, and the specific condition of the forest in question. The science of forests and global change is reviewed with regard to plant responses to enhanced $\mathrm{CO}_{2}$ environments and forests' response to other bioclimatic and indirect factors, such as insect predation, fire, climatic variation and ozone. Three studies of the economic effects of climate change on forests, which project a range of losses and benefits to the economy, are compared. Economic results vary directly with the results of the forest growth and productivity models which were employed as inputs. No one model can provide a complete answer, and current knowledge and models are limited in various ways which point to areas where further research could provide benefits.
\end{abstract}

KEY WORDS: Impacts · Responses · M odeling - Economic · Physiological · Bioclimatic · Ecotype - Tree species

\section{INTRODUCTION}

The forests of the United States encompass many robust, productive ecosystems which have shown great resilience to stress and change over time (Williams 1989, MacCleery 1992). Despite this history, there is substantial concern about how potential changes in climate caused by human activities could affect forests. Research conducted over the past 2 decades suggests that climatic changes could either cause massive redistribution of forests on the continent with large losses in range for important tree species (Smith \& Tirpak 1989), or substantial benefits to the productivity of some forests and a spreading of their range (VEM A P M embers 1995).

*E-mail: winnett.steven@epamail.epa.gov
Temperature and precipitation, two of the climatic factors expected to change with increased greenhouse gas concentrations, are primary determinants of the productivity, health and distribution of forests (Spurr \& Barnes 1980). Several general circulation models (GCMs) predict rising temperatures over the next century and the possibility for large changes in precipitation patterns over various parts of the country (Wilson \& M itchell 1987, Schlesinger \& Zhao 1989, Manabe et al. 1991, Cubasch et al. 1992, M urphy 1995). There is a great deal of uncertainty in the fundamental knowledge of how these potential climatic changes would affect domestic forests, and how those changes would interact with other changes taking place in the biosphere, most notably increasing levels of ozone and acid precipitation. Increases in temperature, for instance, will not necessarily increase growth of trees and may reduce it for some species (Carter 1996). 
Climatic changes may also affect pest and disease regimes, fire, and extreme weather events, which would have additional indirect effects on forests (IPCC 1996a).

Human activities will have a profound impact on how forests respond to climate change. As they have in the past, changes in population and in societal preferences for forest products and other forest resource values could shape forest management and influence species composition and the health of forest resources (Flader 1983, Walker 1991, Langston 1995). Anthropogenic activities and development patterns could block potential species migration pathways (IPCC 1996a). However, humans' ability to manage forests may help mitigate the adverse effects of climate change where it is possible to predict what adaptation strategies will be effective as the atmosphere and climate evolve (IPCC 1996a, Piutti \& Cescatti 1997, Sohngen \& M endelsohn 1998).

One large gap in knowledge is in understanding the path of changes through a transition period from the current climatic regime to some future climatic condition. Currently, there are better estimates of what future climate may look like in response to predicted atmospheric changes than there are estimates about how and how quickly those conditions will arise (IPCC 1996b). The picture of forests in equilibrium in a future climatic regime misses the impact of the changes that will likely take place en route to a new equilibrium. The benefits and costs of climatic changes, should they materialize, will likely depend on that transitional path.

This paper examines the potential impacts of climate change on the forests of the U.S. It explores the various ways forests could be affected by changes in climate, and the effect those changes could have on the economy. The various climate effects, along with sources of uncertainty, and the limitations of the various available tools and analyses are examined.

\section{PREDICTING CHANGES IN FORESTS}

Scientific understanding of the likely effects of changes in climate on forests is based partially on the results of studies using conceptual and mathematical models. Experiments on plant function demonstrate how trees may respond to particular stimuli. Models allow researchers to bring together their understanding of many factors and get a better picture of the potential responses of the forest or ecosystem to climatic, biologic, or atmospheric changes. Each model emphasizes one or more particular process or relationship (Dale \& Rauscher 1994), so results can be very different, even when identical inputs are used.
Early work in modeling projected the response of forest types or species to climate change using historic climate data and pollen records to follow how the distribution of various species was correlated to historic climatic regimes (Overpeck \& Bartlein 1989). Other work applied GCM projections to species' current ranges based on climatic conditions to predict how those ranges would shift (Zabinski \& Davis 1989, Davis $\&$ Zabinski 1992). Many of these studies (Smith \& Tirpak 1989) showed large northward shifts of species' ranges in response to warming. One study (Zabinski \& Davis 1989) showed 4 tree species currently found in most if not all of the eastern U.S. responding to one warming scenario by becoming extinct everywhere but in northern Maine and Canada.

Mathematical computer models examining forest responses range from simple linear regression models (Pan \& Raynal 1995) to more complex representations of biological systems. Many modelers have focused on incorporating physiological processes and detailed responses to climatic factors into their models. These efforts have resulted in the major classes of models primarily used today: the individual tree 'gap' models (e.g. Botkin et al. 1972) and the ecosystem-level models, which include biogeochemistry and biogeography models (VEM AP M embers 1995), and other forest carbon, nitrogen, and water allocation models (e.g. Aber et al. 1995).

Gap models simulate the life cycle of individuals of specific species by modeling trees' response to light, nutrient availability, temperature, and precipitation (Bugmann et al. 1996). Gap models simulate forest stands of multiple species on a period-by-period basis as stands develop and change. Openings or gaps in a stand's canopy create opportunities for new individuals to emerge, or for regeneration to occur. Many of the models simulate the response of trees to changing conditions based on the conditions and range under which the species are observed to grow best (Shugart \& Smith 1996). Outside that range, model processes reduce the species' productivity and regeneration success, and increase their mortality (often simulated as a function of age).

Gap models have produced results showing both increases and decreases in forest productivity, and many results show ecosystem shifts. Botkin et al. (1989) showed large shifts in species types for forests in the Lake States subjected to GCM-projected climate change. Most sites lost productivity and biomass, but the magnitude of change depended on soil and water conditions. Forests on drier or well-drained soils suffered more; some sites with wetter or saturated soils either maintained or improved tree growth as they became somewhat drier. Urban \& Shugart (1989) show species shifts and some dramatic declines in the condi- 
tion of southern pine forests in response to changes. The magnitude of the changes varied with stand age and condition, with older and more stressed stands suffering greater declines. Solomon (1986) showed large ecosystem changes for forests in Eastern North America in response to $\mathrm{CO}_{2}$-induced climate change. Generally, north central and northeast forests gained biomass, and either retained species composition or shifted to an association typically found farther south. Forests growing farther south lost varying amounts of biomass. In another study, Pacific Northwest forests showed mixed results to transient warming that varied with elevation, stand age and initial composition (Urban et al. 1993). Stand structure may itself provide a delayed response to climatic changes. The inertia of large old trees and resilience to stress of vigorously growing mid-size trees may delay by years or centuries shifts in species composition which climatic changes might otherwise have caused more rapidly (Urban et al. 1993, Sykes \& Prentice 1997). Simulations of boreal forest development (Price \& Apps 1996) show results which vary with GCM scenario and site location along a north/south transect. One scenario characterized by large increases in temperature and small increases in precipitation (Geophysical Fluid Dynamics Laboratory; Manabe \& Wetherald 1987) produced large decreases in biomass productivity. Three other GCM scenarios with larger increases in precipitation and a range of temperature increases all produced increases in biomass of varying degrees. Southern sites had changes of greater magnitude than northern sites.

Gap modeling results can show how transient changes in climate affect forests as individual trees' growth responds over time to changing conditions. A drawback of these models is that they may not give sufficient credit to species' abilities to survive, and perhaps do well, under climatic conditions which characterize the edges or outside of their currently observed ranges (Loehle \& LeBlanc 1996). Trees may be more limited by competition from other species than by climatic conditions. At the rates of change currently projected, climatic conditions will likely change faster than the species best adapted to those conditions can successfully migrate into and colonize a new area (Tirpak \& Smith 1989). Until models reflect how individual species will respond to novel conditions in the absence of competition from species better adapted to those conditions, they are likely to understate the resilience and adaptability of the forest.

The potential speed with which trees can migrate into an area with more advantageous conditions is an important concern. Historic changes in forest distribution due to the ice age and other events took place over thousands of years (Davis 1981), at rates of less than 30 miles ( $-48 \mathrm{~km}$ ) per century (Davis \& Zabinski 1992). Scientists and policy makers examining possible changes in climate due to current patterns of land and fossil fuel energy use predict significant changes over the next $100 \mathrm{yr}$ (IPCC 1994). Migration rates of 350 miles $(-560 \mathrm{~km})$ per century could be required to maintain species near their current climatic ranges under some scenarios of climate change (IPCC 1996a). Such migration rates are unlikely to occur in the absence of human intervention. Should species respond poorly to climatic regimes outside their current range, and in the absence of super-natural rates of in-migration by better adapted species, many forest types will decline in parts of their current locations (Tirpak \& Smith 1989).

Simpler models of forest growth display results similar to those of the gap models. Two regression models of forest growth (Pan \& Raynal 1995) showed that different plantation conifers respond in different ways to changes in temperature and precipitation. Increases or decreases in growth were greatly affected by local stand conditions and the relative drought tolerance of the species.

Two classes of models which simulate changes in broader ecosystem types have generated results with both net benefits and losses to productivity and forest area in response to climatic changes. Biogeography models simulate the geographic distribution of ecosystems through analysis of an ecosystem's response to ecophysiological constraints imposed by climatic conditions, and to limitations in basic resources such as water, light, and nitrogen (e.g. Neilsen 1995). These models show how the distribution of ecotypes changes from one equilibrium state to another, though they cannot indicate the condition of those systems. Biogeochemistry models simulate ecosystem productivity and carbon storage over time by analyzing the response of soil and plant processes to changes in carbon and nutrient cycles imposed by environmental inputs (e.g. McGuire et al. 1995). Their results on ecosystem carbon density are one measure of forest stand density, and a loss in carbon is one indication of stand dieback or die-off. The biogeochemistry models cannot, however, show how different ecosystems are distributed over the landscape.

One study (VEM AP M embers 1995) linked 3 of each of these model types in combinations, using the different climatic scenarios, to project both the distribution and condition of ecotypes arising once climate changes have equilibrated. The results show both losses and gains to the area of specific forest types, losses and gains of ecosystem carbon, and continental-scale changes in productivity of -1 to $40 \%$. The results strongly depend on the GCM scenario and models used. Only results which include the physiological effects of increased $\mathrm{CO}_{2}$ are discussed here.

In the GCM scenario with the largest increases in temperature (United Kingdom Meteorological Office 
model; Wilson \& Mitchell 1987), the biogeography models all completely replace the eastern temperate deciduous forest with the southern pine forest ecotype across its entire current range. The current northeast and northern Lake States forests are eliminated from the continental U.S. in all but the Oregon State University GCM scenario (Schlesinger \& Zhao 1989), which has the smallest increases in temperature of the 3 GCM scenarios used. One of the biogeography models replaces most if not all of the current Pacific N orthwest coastal coniferous forest with a southern forest type coniferous forest, while the other models maintain most or all of that area with its current cover. Results for the interior west forests are mixed amongst models and climate scenarios, showing either changes or maintenance of existing forest types.

Across the GCM scenarios, the biogeochemistry models project increasing and decreasing productivity for the southern, north central, and northwest forest types in response to climate changes. Two of the models show general increases in productivity for interior west forests, and all models show increases for the northeast. One of the biogeochemistry models projects losses of carbon over virtually the entire eastern half of the U.S. and varied small magnitude changes elsewhere. Mixed results characterize the other models' carbon projections.

These models are valuable in that they allow for the inclusion of a number of factors in ecosystem structure and function at a scale that is appropriate to the natural scale of the general circulation models. However, they do not account for differences between individual species within these broad ecosystem classes (types such as maritime temperate conifer forests and warm temperate mixed/evergreen forest). Consequently, the models may show general increases in the productivity and areal extent of an ecosystem without recognizing that individual species might be either dying out or thriving over all or part of their range. The interaction and dynamics within a multi-species community may itself influence the strength of the system's reaction to increased $\mathrm{CO}_{2}$. In simulations of a forest with multiple species versus simulations of a single species designed as the average of the community, Bolker et al. (1995) showed that species differences and community diversity may play a large role in determining ecosystem function over time scales appropriate for the assessment of climate change impacts.

The transition from current to future climate may be accompanied by increased stresses, dieback, reproductive failures, and a forced adaptation of the human and nature systems to differing conditions before, and if, a stable situation is reached. Although the resulting changes may be positive for important factors, ignoring the transitional path and how existing forests will react to changes may miss the full costs of the change. Due to the current limitations of the biogeography models, analyses using them cannot assess these transitional changes.

\section{PHYSIOLOGICAL FACTORS}

In addition to its role as the most prevalent greenhouse gas, carbon dioxide is a primary input to the growth and development of all plant life. Much discussion has centered on the role of increasing atmospheric concentrations of $\mathrm{CO}_{2}$ in providing both a fertilization effect on vegetation and an increase in the efficiency with which plants use water (Bazzaz 1990, McGuire \& J oyce 1995, Bazzaz et al. 1996). Both of these factors represent potentially significant benefits to forests and other plant populations.

Carbon fertilization has been demonstrated in controlled settings for tree seedlings (Bazzaz 1990, Groninger et al. 1995). In the laboratory and growth chambers, the growth rate and productivity of plants increased in the presence of higher concentrations of carbon dioxide. In an 8 yr study using open-top growth chambers, sour orange tree seedlings in an enhanced $\mathrm{CO}_{2}$ environment grew more than twice as fast as similar seedlings growing in ambient air over the initial years of the experiment (Idso \& Kimball 1997). In other experiments, the response to elevated levels of $\mathrm{CO}_{2}$ differed among species, including those that co-occur, with shade tolerant species exhibiting the largest increase in growth (Bazzaz et al. 1990, Kinney \& Lindroth 1997). This suggests that changes in carbon dioxide levels may change the competitive dynamics among species. The fertilization effect may also depend on the availability of water and nutrients (McGuire \& Joyce 1995). To date, such growth increases have been conclusively demonstrated for only juvenile individuals (Shugart \& Smith 1996). Research has also shown that fertilization effects sometimes diminish after an initial period of adjustment (Bazzaz et al. 1996), and there is still much uncertainty regarding how much of a long-term effect can be expected. These experiments all present problems in scaling their results to forest ecosystems given the small size of the individuals studied, the fraction of trees' life span involved, and the comparative simplicity of the system being examined.

Free Air Carbon Enrichment (FACE) experiments expose more mature trees to increased $\mathrm{CO}_{2}$ levels, often in a forest environment (Hendrey et al. 1993). In $1 \mathrm{yr}$ of a FACE experiment in North Carolina, dominant loblolly pine trees growing in an enhanced $\mathrm{CO}_{2}$ environment grew at a rate approximately $27 \%$ greater than trees growing in ambient conditions (E. H. 
DeLucia et al. unpubl. data). The net photosynthetic rate measured in the needles was approximately $65 \%$ greater than that measured in ambient air (Ellsworth et al. 1995). Questions about long term adjustments by plants to higher concentrations of $\mathrm{CO}_{2}$ are not able to be answered by such early results. While offering promising opportunities to study carbon fertilization and other effects in complex ecosystem conditions, FACE and other carbon enrichment experiments present the additional problem of translating results generated by 'stepping up' carbon concentrations to situations where concentrations are changing gradually over the life of trees (Bazzaz et al. 1996).

Researchers have demonstrated increases in water use efficiency with increasing concentrations of carbon dioxide (Bazzaz et al. 1996, Groninger et al. 1996). The improvement in efficiency can vary amongst species and with different temperatures. Water use efficiency improvements on a large scale could have profound effects on forests in light of possible decreases in precipitation attending changes in climate, as plants would be able to function better under drier conditions. Improvements in water use efficiency may not completely offset the effects of reduced precipitation and/or increased temperatures in all situations. For example, the relative enhancement of water use efficiency associated with enhanced $\mathrm{CO}_{2}$ may be reduced or eliminated in response to drought (LeThiec \& Dixon 1996). In addition, some results suggest that trees may acclimatize to increased $\mathrm{CO} 2$ levels over the long run, thus reducing the enhancement in water use efficiency initially experienced by the tree (LeThiec \& Dixon 1996). One theory proposes that $\mathrm{CO}_{2}$-enhanced water use efficiency may cause increased damage to vegetation. Bassow et al. (1994) suggest that since higher $\mathrm{CO}_{2}$ concentrations increase water use efficiency by reducing leaf conductance of water, such changes will lead to less cooling of leaves by transpiration, resulting in more heat damage during extreme heat events. Results of the FACE experiments in mature loblolly pine stands show little to no change in leaf conductance of water in response to elevated $\mathrm{CO}_{2}$ concentrations (Ellsworth et al. 1995), though these results do not necessarily rule out the possibility of beneficial changes in water use efficiency in deciduous trees or other conifers under similar conditions.

Modeling work simulating tree physiology has demonstrated large benefits to certain species of trees from increased $\mathrm{CO}_{2}$ concentrations. In one study, researchers projected that higher concentrations of $\mathrm{CO}_{2}$ increased growth of loblolly pine in the southern U.S. (Valentine et al. 1997). The effect was sufficient to offset any detrimental effects of changes in temperature and precipitation, and provided net benefits to forest productivity. However, increasingly higher temper- atures reduced the magnitude of the benefit. Growth of ponderosa pine increased by 29 and $13 \%$, respectively, in response to increases in $\mathrm{CO}_{2}$ and temperature, and by $49 \%$ when both were increased simultaneously (Constable et al. 1996). Application of increased ozone reduced growth 1, 19, and 39\%, respectively, from simulated levels. An ecosystemlevel modeling study which considered the effect of both climatic changes and increases in water use efficiency showed that higher $\mathrm{CO}_{2}$ levels reduced the magnitude of forest displacement relative to a case where the effects of increased $\mathrm{CO}_{2}$ were not accounted for (N eilsen \& Marks 1994).

Increased carbon dioxide levels may also trigger changes in the chemical composition of vegetation. Research has shown that increased $\mathrm{CO}_{2}$ may increase the carbon-nitrogen ratio of leaves (Fajer et al. 1989). Such a change would reduce the nutritional value of vegetation to insects and force insect herbivores to consume more vegetation to meet their nutritional needs (Bazzaz \& Fajer 1992). Insects feeding on vegetation grown in high $\mathrm{CO}_{2}$ environments increase their consumption by 20 to $80 \%$ (Bazzaz 1990). Despite the lack of evidence that such behavior always leads to improvement in the long-term success of pest species, such increases in direct consumption of vegetation might offset some or all of the benefit of increased $\mathrm{CO}_{2}$ to trees.

\section{DIRECT AND INDIRECT CLIMATIC EFFECTS}

Recent GCM scenarios which feature transient views of how the climate will change over time give a range of results for temperature increases and changes in precipitation (M anabe et al. 1991, Cubasch et al. 1992, Murphy 1995). Temperatures are generally predicted to increase across the United States, with some areas experiencing larger changes than others. Predicted changes in precipitation are less consistent. Different regions experience either increased or decreased precipitation.

These changes in climate may increase forests' susceptibility to wildfire. In areas of the west which experience significant yearly danger of forest fire, there are projections of no change in precipitation or substantial drying accompanying projected rises in temperature (M anabe et al. 1991, Cubasch et al. 1992, Murphy 1995). Either of these dynamics could result in a higher probability of catastrophic fires, but decreases in precipitation would likely increase that danger substantially. Historically, occurrence of fire in western forests has varied directly with variations in temperature, and varied inversely with fluctuations in precipitation (Swetnam 1993). Forests in the western states already suffer the effects of deprivation of normal fire regimes, 
and of insect infestation (Sampson et al. 1994). These conditions have led to unprecedented losses of timberlands to catastrophic fires in recent years as stand structures have departed from their historic range of variability.

Increasing variability of climatic factors may also have a detrimental effect on forests. Plants rely on a certain range in seasonal temperatures and precipitation for proper function in their various life stages. Extremes in variation outside of an acceptable range can damage individuals so that they die or their function is impaired (Bassow et al. 1994). Until the spring thaw arrives, trees function best if temperatures stay low, lest a prolonged early thaw bring them out of the protection of winter dormancy. Once trees emerge from dormancy, extreme cold can damage them.

Large-scale incidents of forest dieback have been positively correlated with extreme weather events (Auclair et al. 1990, 1996). Declines observed in various forest ecosystems have corresponded to repeated freeze-thaw events in the winter, followed by severe droughts in the summer. Some of these studies have also described the processes causing the physiological damage which leads to the diebacks (Auclair et al. 1990). Should climatic changes lead to periods of significant warming within the winter period, or extreme heating, cooling, or drought during the summer, more such large-scale events are possible. These types of damage can make forests more susceptible to threats from pests, or to diseases. Although no positive connection has yet been made between projected changes in climate and an increase in climate variability or extreme weather events, researchers have postulated the existence of such an effect (Auclair et al. 1996).

Trees are constantly under attack by a set of insect pests, which under normal conditions they are generally able to either survive the effects of or fend off. Trees under abnormal temperature or moisture stress are less able to defend themselves from attack and may suffer more losses (Logan et al. 1995). In addition, increases in temperature may increase the growing season and growth rate for some pests, thus allowing them more generations in a year (IPCC 1996a). Pests may have greater reproductive success during that year through the greater success they have attacking the forest. The combination of greater stress and more numerous attacks from pests may lead to greater mortality.

Damage to forest vegetation has been linked to increasing levels of tropospheric ozone and acid precipitation. Although some acid precipitation may add the nutrient nitrogen to the forest, the application of acid mist lowers the ability of red spruce to tolerate cold (Strimbeck et al. 1995). Ozone is a known phytotoxin which works through a number of pathways to reduce growth and cause direct damage to various species (Hom 1997). Its effects may be amplified by other stresses, such as low soil moisture and higher temperatures, to cause greater growth losses or damage (M cLaughlin \& Downing 1995, 1996). Studies have shown mixed impacts of ozone on forests which were either maintained or grew with time. Teskey (1995) showed a $5 \%$ annual growth reduction in southern pine forests in response to ozone. In another study, elevated ozone levels caused ponderosa pine seedlings greater growth reduction in the second year of exposure than in the first (Takemoto et al. 1997). In a $2 \mathrm{yr}$ study of 3 northeastern hardwood species, cherry suffered growth and biomass reductions which increased with increasing ozone levels, yellow poplar increased growth and biomass with increasing ozone levels, and sugar maple showed no effects to any levels of ozone (Rebbeck 1996).

Finally, changes in climate and/or atmospheric chemistry are likely to affect the soil and ecosystem processes by which nutrients are stored, released, and recycled, or lost to the system (Pastor \& Post 1988). Decompositional processes and the activities of soil micro-organisms, which have a significant role in determining the structure, function and health of forests, change with moisture, temperature, and litter quality. These processes are also affected by changes in species composition, which is sensitive to changes in climatic variables (Post \& Pastor 1996). Changes in any of these factors can significantly change the nutrient cycling regime and function of an ecosystem (Bazzaz et al. 1996).

\section{ECONOMIC IMPACTS}

Several studies have examined the potential economic impacts of climatic changes on forests. These studies have used different types of forest models, and their results largely reflect the character of those models.

Callaway et al. (1994) used gap model results to scale the change in growth of forest types regionally. In the study, softwood growth in the southern and south central states declined precipitously (56 to $100 \%$ ), while softwood growth in both the north central and northeastern states decreased 40 to $78 \%$. Softwood yields in the western states ranged more widely between growth increases and decreases (-53 to $+79 \%$ ). Hardwood growth in the north increased 11 to $71 \%$, while growth in the south and south central regions ranged from -60 to $+20 \%$. The study used an optimization model of U.S. private timber markets (Adams et al. 1996) to assess how these productivity changes would affect the forest product sector. 
Table 1. Base welfare and changes in welfare (in \%) for a forest impact study using gap model data and a dynamic model of the U.S. forest sector for 2 levels of temperature change with and without simulated $\mathrm{CO}_{2}$ fertilization ('fert.') effects. Source: Callaway et al. (1994)

\begin{tabular}{|lccccc|}
\hline Net present value & Base (millions of $\$$ ) & $2.5^{\circ} \mathrm{C}$ with fert. & $2.5^{\circ} \mathrm{C}$ & $4.0^{\circ} \mathrm{C}$ with fert. & $4.0^{\circ} \mathrm{C}$ \\
\hline Firm and producer surplus & 1377125 & -17.4 & -33.5 & -28.3 & -42.1 \\
Landowner surplus & 93934 & 146 & 237 & 194 & 208 \\
Foreign trade surplus & 7856 & -21.8 & -39.3 & -35.6 & -50.1 \\
Total surplus & 1571815 & -4.3 & -10.7 & -9.4 & -18.7 \\
\hline
\end{tabular}

Decreases in softwood yields in the economically important southern region dominated the results. Although the large area of northern hardwoods increased in value, its contribution to the overall economy was insufficient to offset the softwood domination of the market (see Table 1). Total welfare decreased significantly in response to increased warming, and a simulated growth enhancement, designed to show how potential carbon fertilization might affect the results, diminished the economic damage slightly. Overall, the increased scarcity of timber and the corresponding rise in prices makes the remaining resource very valuable, and the welfare of land and timber owners rose in response. These economic improvements were insufficient, however, to reverse the losses to firms and consumers, whose economic welfare dominates the function of the sector (base level contributions of participant welfare to the sector; Table 1).

Mills \& Haynes (1995) examined how different climate change scenarios would affect demand and supply for wood products in the U.S. forest sector. They used a biogeochemistry model (Terrestrial Ecosystem M odel; M cGuire et al. 1992) to project changes in forest productivity for broad ecosystem types, in response to 4 GCM predictions of future climate. Percent changes in net primary productivity (NPP) from TEM were translated to changes in net forest growth in the TAMM/ ATLAS forest sector model (Adams \& Haynes 1980). TEM is one of the 3 biogeochemistry models used in the Vegetation/Ecosystem Modeling and Analysis Project study (VEM AP M embers 1995). In comparison with the other 2 models, TEM results are generally the most positive with regard to changes in NPP and carbon storage.

Changes in growth were almost uniformly positive, with some forest types experiencing growth increases of up to $29 \%$. Differences between maximum and minimum responses were most variable for the southern U.S., but only in 5 cases out of 159 (minimum, mean, maximum for 53 forest types) were there growth declines. Increases in the growth response occurred linearly over time, so most of the gains in inventory ( 3 to $22 \%$ ) occurred late in the projection period (1990 to 2040). Even so, softwood inventories increased over base levels, with corresponding declines in softwood timber prices. Timber harvests increased 1 to $3 \%$, with most of the increases occurring for softwood production. Hardwood harvests declined in the maximum case. Increased production and lower prices reduced imports of timber from Canada and increased demand for timber over non-wood substitutes.

A third study (Sohngen \& Mendelsohn 1998) showed a range of economic benefits to the forest sector in response to climate change. Benefits ranged from 1 to $11 \%$ of the net market surplus in the forest sector. The study used results of the VEM AP study (VEM AP M embers 1995) to assess the impact of various GCM scenarios on the U.S. forest sector. Using a dynamic model of the forest economy, researchers projected the economic impacts on domestic markets of various levels of climatic changes. They scaled the carbon storage (as a measure of ecosystem biomass) and area change projections generated by the biogeography and biogeochemistry models used in the study into several levels as shown in Table 2 . In addition, they assessed the sensitivity of the results to various assumptions about the timing and scale of climatic changes and ecosystem responses, the nature and success of human responses, and the economic response.

The results of this study reflect the ecosystem modeling results, and are driven more by changes in forest area than by changes in biomass. Generally, these models show an increase in the area of the most eco-

Table 2. Ranges for change in net present value of forest sector market surplus (billions of $\$, \%$ change in parentheses) from baseline across combinations of ecological models simulating forest responses to $3 \mathrm{GCM}$ scenarios. Source: Sohngen $\&$ Mendelsohn (1998)

\begin{tabular}{|ccc|}
\hline $\begin{array}{c}\text { Precipitation } \\
\text { change (\%) }\end{array}$ & \multicolumn{2}{c|}{$\begin{array}{c}\text { Temperature change } \\
+2.5^{\circ} \mathrm{C}\end{array}$} \\
\hline 7 & $\$ 2.2-18.0$ & $\$ 11.9-35.3$ \\
& $(1-6 \%)$ & $(3-11 \%)$ \\
15 & $\$ 10.8-28.2$ & $\$ 1.13-32.6$ \\
& $(3-9 \%)$ & $(0.5-10 \%)$ \\
& & \\
\hline
\end{tabular}


nomically important forest types (southern pines) at the expense of forests contributing less to the forest economy (temperate deciduous and northern softwood types). Although some of the carbon storage results were negative, the increase in the area of the forest type involved more than made up for the per acre loss in biomass. The net result was greater timber inventories of the most valuable types, and greater income to the forest sector. Several other aspects are noteworthy.

Unlike the results of the Callaway et al. (1994) study, economic benefits increased with greater temperatures. Secondly, results in this study varied dramatically across model combinations. One model combination used projects decreases in biomass across all forest types, while the other projects all increases. Likewise, the size of the Pacific Northwest maritime forest types declined in one combination and increased in the other. Although the size of the southern pine forest increased in both combinations, one model projects nearly half the increase displayed by the other.

These results also offer some insights into the value of human intervention. A set of sensitivity analyses simulated in a simplified fashion show how management activities might affect the results. Adaptive regeneration of affected sites with better adapted species, following harvest, slightly increased welfare in the forest sector, compared to allowing the forest to die back and regenerate itself naturally. Net economic losses or significantly less gain resulted if managers guessed wrong about which species to plant, and a time lag in successful regeneration ensued. High intensity salvage of affected trees also improved the economic results, compared to lesser levels of salvage. Levels of market demand greater than the base case had dramatic consequences to the forest sector, increasing by 2 to 3 times in most cases the benefits accruing from climatic changes. Demand lower than base levels did not necessarily correlate with decreased benefits.

\section{CONCLUSIONS}

Most significant in the understanding of potential effects of climatic changes on domestic forests is the variation and uncertainty in the results of studies which define what is known. In some cases, there is good scientific agreement on the nature of the physiological processes, but less so on how those translate into effects at the forest level. In some cases not enough is known about the potential effects to make concrete projections.

The analyses discussed here display examples of the types of effects which forests could experience as changes in the composition of the atmosphere induce changes in climatic regimes. Researchers compare climatic regimes induced by historic or current atmospheric conditions with regimes induced by some future condition. Preindustrial or current levels of $\mathrm{CO}_{2}$ and either 2 or 4 times those levels are often used as endpoints for analyses (e.g. Solomon 1986, VEMAP Members 1995, IPCC 1996a). However, these are unlikely to be the endpoints of potential changes in climate. In the absence of measures sufficient to prevent changes, these future atmospheric conditions and the climatic regimes they induce are likely to be points along a path of constant change. The changes in forests given as the results of such analyses are likewise points in a continuum of changes that do not necessarily constitute the magnitude, type, or direction of changes which could occur. Further atmospheric and climatic changes beyond the standard points of analysis could bring very different results, as could greater understanding of all the interactions within ecosystems and of the factors influencing them.

Overall, study results indicate that forests' response to climate change will depend on local conditions. Stand age, site soil and moisture characteristics, species composition, and the history of disturbance and development may all affect how and how quickly forests respond to rising temperatures, changes in precipitation patterns, and the other ecological and biophysical changes which those conditions induce. Forests growing under optimal conditions may do well depending on the nature and severity of change; trees which can accept a greater range of conditions will fare better than those with narrow ecological requirements. Forests under stress are likely to be further stressed unless climatic changes mitigate the situation. The condition of trees growing in soils too moist for optimal growth may improve if rising temperatures dry the site. Forests on marginal sites may deteriorate if climatic changes make conditions less conducive to survival. Forests already stressed by crowding, pathogens, or atmospheric conditions may not survive the additional climatic stress.

A prominent feature of the field is that the type of analytic or research tool used to assess the potential effects of climatic changes can largely determine whether the outcome is positive or negative. The modeling results illustrate this point. Gap modeling results have shown both positive and negative effects of potential climatic changes on individual species and forest types. Biogeography models show expansions of some forest types and shrinkage of others, in some cases directly disagreeing over the effects of the same climatic regimes. Biogeochemistry and other forest carbon models show both increasing and decreasing 
productivity and biomass of important forest types, again sometimes in disagreement with each other on the same scenarios. These disagreements have been shown to significantly affect the modeled economic impacts, in some cases attributing opposite signs (negative or positive) to the different results.

Each of various types of models simplifies forest systems in ways which focus on some important component of their structure and function. Not all the models are sensitive to the effects of enhanced $\mathrm{CO}_{2}$ on forests. One class of models (the biogeography models) are currently unable to project the effects of gradual climatic transition on forests, while another class of models which can (the biogeochemistry models) are seldom used to do so in the published literature. The relative uncertainty in the knowledge of the climate's transitional path complicates the study of how forests will respond to those changes.

Several types of forest models do not recognize the contribution and sensitivity of individual species to changes in an ecosystem's bioclimatic conditions. The major economic models currently in use permit no detail beyond the classification of hardwoods and softwoods. As many local and regional economies depend on the condition of particular tree species within a broad ecosystem type, this is likely to be an important consideration. Such impacts may not show up in an assessment of impacts at the national level. That possibility argues for more detailed regional or local assessments of the potential effects of climate change on forests.

As no model accounts adequately for all of the components important to determining forests' response to climate change, it is important that no model's projections be taken as the ultimate answer. All results need to be viewed with an eye to what they say about a piece of the whole picture and how they help reduce the uncertainty in the understanding of these issues. Important advances are likely as scientists and modelers with differing viewpoints work together through projects such as VEMAP. Such advances will require better information and data on climatic projections and ecosystem structure and function with which to build the needed tools. Already, new types of models are being proposed which bring together the strengths of the various classes of models now being used (Nikolov 1995). Uncertainty in the projections of future climate is probably as influential in the results of impact studies as are the differences and gaps in the understanding of how forests will respond to those conditions.

Acknowledgement. The author thanks Dr Richard Birdsey for his assistance.

\section{LITERATURE CITED}

Aber JD, Ollinger SV, Federer CA, Reich PB, Goulden ML, Kicklighter DW, Melillo J M, Lathrop RG (1995) Predicting the effects of climate change on water yield and forest production in the northeastern United States. Clim Res 5: 207-222

Adams DM, Alig R, McCarl BA, Callaway J M, Winnett SM (1996) An analysis of the impacts of public timber harvest policies on private forest management in the U.S. For Sci 42(3):343-358

Adams DM, Haynes RW (1980) The 1980 Softwood Timber Assessment Market Model: structure, projections, and policy simulations. For Sci Monogr 22

Auclair AND, Lill JT, Revenga C (1996) The role of climate variability and global warming in the dieback of northern hardwoods. Water Air Soil Pollut 91:163-186

Auclair AND, Martin HC, Walker SL (1990) A case study of forest decline in western Canada and the adjacent United States. Water Air Soil Pollut 53:13-31

Bassow SL, M cConnaughay KDM, Bazzaz FA (1994) The response of temperate tree seedlings grown in elevated $\mathrm{CO}_{2}$ to extreme temperature events. Ecol Appl 4(3):593-603

Bazzaz FA (1990) The response of natural ecosystems to the rising global $\mathrm{CO}_{2}$ levels. Annu Rev Ecol Syst 21:167-196

Bazzaz FA, Bassow SL, Berntson M, Thomas SC (1996) Elevated $\mathrm{CO}_{2}$ and terrestrial vegetation: implications for and beyond the global carbon budget. In: Walker B, Steffen $\mathrm{W}$ (eds) Global change and terrestrial ecosystems. Cambridge University Press, Cambridge, p 43-76

Bazzaz FA, Coleman J S, M orse SR (1990) Growth responses of seven major co-occurring tree species of the northeastern United States to elevated $\mathrm{CO}_{2}$. Can J For Res 20: 1479-1484.

Bazzaz FA, Fajer ED (1992) Plant life in a $\mathrm{CO}_{2}$-rich world. Sci Am 266(1):68-74

Bolker BM, Pacala SW, Bazzaz FA, Canham CD, Levin SA (1995) Species diversity and ecosystem response to carbon dioxide fertilization: conclusions from a temperate forest model. Global Change Biol 1:373-381

Botkin DB, J anak J G, Wallis J R (1972) Some ecological consequences of a computer model of forest growth. J Ecol 60 : 849-872

Botkin DB, Nisbet RA, Reynales TE (1989) Effects of climate change on forests of the great lake states. In: Smith J B, Tirpak DA (eds) The potential effects of global climate change on the United States, Appendix D: Forests. EPA230-05-89-054. U.S. Environmental Protection Agency, Washington, DC (Chapter 2)

Bugmann HKM, Xiaodong $Y$, Sykes MT, M artin P, Lindner $M$, Desanker PV, Cumming SG (1996) A comparison of forest gap models: model structure and behavior. Clim Change 34:289-313

Callaway M, Smith J, Keefe S (1994) The economic effects of climate change for U.S. forests. Contractor report to U.S. EPA. RCG/Hagler Bailly, Boulder, CO

Carter KK (1996) Provenance tests as indicators of growth responses to climate change in 10 north temperate tree species. Can J For Res 26:1089-1095

Constable JVH, Taylor GE, Laurence J A, Weber J A (1996) Climatic change effects on the physiology and growth of Pinus ponderosa: expectations from simulation modeling. Can J For Res 26:1315-1325

Cubasch U, Hasselmann K, Hock H, Maier-Reimer E, Mikolajewicz U, Santer BD, Sausen R (1992) Time-dependent greenhouse warming computations with a coupled oceanatmosphere model. Clim Dynam 8:55-69 
Dale VH, Rauscher HM (1994) Assessing impacts of climate change on forests: the state of biological modeling. Clim Change 28:65-90

Davis M B (1981) Quaternary history and the stability of forest communities. In: West DC, Shugart HH, Botkin DB (eds) Forest succession. Springer-Verlag, New York, p 132-153

Davis M B, Zabinski C (1992) Changes in geographical range resulting from greenhouse warming: effects on biodiversity in forests. In: Peters RL, Lovejoy TE (eds) Global warming and biological diversity. Yale University Press, New Haven, CT, p 297-308

Ellsworth DS, Oren R, Huang C, Phillips N, Hendrey GR (1995) Leaf and canopy responses to elevated $\mathrm{CO}_{2}$ in a pine forest under free-air $\mathrm{CO}_{2}$ enrichment. Oecologia 104: 139-146

Fajer ED, Bower MD, Bazzaz FA (1989) The effects of enriched carbon dioxide atmospheres on plant-insect herbivore interactions. Science 243:1198-1200

Flader S (1983) The Great Lakes forest: an environmental and social history. University of M innesota Press, M inneapolis, and Forest History Society, Santa Cruz

Groninger JW, Seiler J R, Zedaker SM, Berang PC (1995) Effects of elevated $\mathrm{CO}_{2}$, water stress, and nitrogen level on competitive interactions of simulated loblolly pine and sweetgum stands. Can J For Res 25:1077-1083

Groninger J W, Seiler J R, Zedaker SM, Berang PC (1996) Photosynthetic response of loblolly pine and sweetgum seedling stands to elevated carbon dioxide, water stress, and nitrogen level. Can J For Res 26:95-102

Hendrey GR, Lewin KF, Nagy J (1993) Free air carbon dioxide enrichment: development, progress, results. Vegatatio 104/105:17-31

Hom J (1997) Multiple stress studies on forest tree species. In: Birdsey R, Mickler R, Sandberg D, Tinus R, Zerbe J, O'Brian K (eds) USDA Forest Service Global Change Research Program highlights: 1991-1995. USDA Forest Service Gen Tech Rep NE-237. U.S. Department of Agriculture, Forest Service, Northeastern Forest Experiment Station, Radnor, PA, p 61-65

Idso SB, Kimball BA (1997) Effects of long-term atmospheric $\mathrm{CO}_{2}$ enrichment on the growth and fruit production of sour orange trees. Global Change Biol 3:89-96

IPCC (Intergovernmental Panel on Climate Change) (1994) Policy summary. IPCC Secretariat, UNEP, Geneva

IPCC (Intergovernmental Panel on Climate Change) (1996a) Climate change 1995-impacts, adaptations and mitigation of climate change: scientific-technical analyses. Watson RT, Zinyowera MC, Moss RH, Dokken DJ (eds) Cambridge University Press, Cambridge

IPCC (Intergovernmental Panel on Climate Change) (1996b) Climate change 1995-the science of climate change. Houghton J T, Meira Filho LG, Callander BA, Harris N, Kattenberg A, Maskell $K$ (eds) Cambridge University Press, Cambridge

Kinney KK, Lindroth RL (1997) Responses of three deciduous tree species to atmospheric $\mathrm{CO}_{2}$ and soil $\mathrm{NO}_{3}{ }^{-}$availability. Can J For Res 27:1-10

Langston N (1995) Forest dreams, forest nightmares: the paradox of old growth in the Inland West. University of Washington Press, Seattle

LeThiec D, Dixon M (1996) Acclimation of photosynthesis in Norway spruce and red oak grown in open top chambers and subjected to natural drought and to elevated $\mathrm{CO}_{2}$. Can J For Res 26:87-94

Loehle C, Leblanc D (1996) Model-based assessments of climate change effects on forests: a critical review. Ecol Model 90:1-31
Logan J A, Bolstad PV, Bentz BJ , Perkins DL (1995) Assessing the effects of changing climate on mountain pine beetle dynamics. In: Tinus RW (ed) Report of Interior West Global Change Workshop. USDA Forest Service Gen Tech Rep RM-GTR-262. U.S. Department of Agriculture, Fort Collins, CO, p 92-105

MacCleery DW (1992) American forests: history of a resilient resource. Forest History Society, Durham, NC

M anabe J FB, Wetherald RT (1987) Large scale changes in soil wetness induced by an increase in carbon dioxide. J Atmos Sci 44:1211-1235

Manabe S, Stouffer RJ, Spelman MJ, Bryan K (1991) Transient responses of a coupled ocean-atmosphere model to gradual changes of atmospheric $\mathrm{CO}_{2}$. Part 1: Annual mean response. J Clim 4:785-818

McGuire AD, J oyce LA (1995) Responses of net primary production to changes in $\mathrm{CO}_{2}$ and climate. In: J oyce LA (ed) Productivity of America's forests and climate change. USDA Forest Service Gen Tech Rep RM-GTR-217. U.S. Department of Agriculture, Fort Collins, CO, p 9-45

McGuire AD, J oyce LA, Kicklighter D, M elillo J M, Esser G, Vörösmarty CJ (1992) Interactions between carbon and nitrogen dynamics in estimating net primary productivity for potential vegetation in North America. Global Biogeochem Cycles 6:101-124

McGuire AD, Melillo J M, Kicklighter DW, J oyce LA (1995) Equilibrium responses of soil carbon to climate change: empirical and process-based estimates. J Biogeogr 22

McLaughlin SB, Downing DJ (1995) Interactive effects of ambient ozone and climate measured on growth of mature forest trees. Nature 374:252-254

McLaughlin SB, Downing DJ (1996) Interactive effects of ambient ozone and climate measured on growth of mature loblolly pine trees. Can J For Res 26:670-681

Mills J R, Haynes RW (1995) Influence of climate change on supply and demand for timber. In: J oyce LA (ed) Productivity of America's forests and climate change. USDA Forest Service Gen Tech Rep RM-GTR-217. U.S. Department of Agriculture, Fort Collins, CO, p 46-55

Murphy J M (1995) Transient response of the Hadley Centre Coupled Model to increasing carbon dioxide. Part 1. Control climate and flux adjustment. J Clim 8:36-56

Neilsen RP (1995) A model for predicting continental-scale vegetation distribution and water balance. Ecol Appl 5(2): 362-385

Neilsen RP, Marks D (1994) A global perspective of regional vegetation and hydrologic sensitivities from climatic change. J Veg Sci 5:715-730

Nikolov NT (1995) Modeling transient response of forest ecosystems to climatic change. In: Tinus RW (ed) Report of Interior West Global Change Workshop. USDA Forest Service Gen Tech Rep RM-GTR-262. U.S. Department of Agriculture, Fort Collins, CO, p 92-105

Overpeck JT, Bartlein PJ (1989) Assessing the response of vegetation to future climate change: ecological response surfaces and paleoecological model validation. In: Smith J B, Tirpak DA (eds) The potential effects of global climate change on the United States, Appendix D: Forests. EPA230-05-89-054. U.S. Environmental Protection Agency, Washington, DC (Chapter 1)

Pan Y, Raynal DJ (1995) Predicting growth of plantation conifers in the Adirondack Mountains in response to climate change. Can J For Res 25:48-56

Pastor J , Post WM (1988) Response of northern forests to $\mathrm{CO}_{2}$ induced climate change. Nature 334:55-58

Piutti E, Cescatti A (1997) A quantitative analysis of the interactions between climatic response and intraspecific com- 
petition in European beech. Can J For Res 27:277-284

Post WM, Pastor J (1996) LINKAGES - an individual-based forest ecosystem model. Clim Change 34:253-261

Price DT, Apps MJ (1996) Boreal forest responses to climatechange scenarios along an ecoclimatic transect in central Canada. Clim Change 34:179-190

Rebbeck J (1996) Chronic ozone effects on three northeastern hardwood species: growth and biomass. Can J For Res 26: 1788-1798

Sampson RN, Adams DL, Hamilton SS, Mealey SP, Steele R, Van De Graaff D (1994) Assessing forest ecosystem health in the Inland West. J Sustain For 2(1/2):3-12

Schlesinger ME, Zhao ZC (1989) Seasonal climate changes induced by doubled $\mathrm{CO}_{2}$ as simulated by the OSU atmospheric GCM-mixed layer ocean model. J Clim 2:459-495

Shugart HH, Smith TM (1996) A review of forest patch models and their application to global change research. Clim Change 34:131-153

Smith J B, Tirpak DA (1989) The potential effects of global climate change on the United States. EPA-230-05-89-054. U.S. Environmental Protection Agency, Washington, DC

Sohngen BL, M endelsohn RO (1998) The U.S. timber market impacts of climate change. In: Mendelsohn R, Neumann JE (ed) The impact of climate change on the United States economy. Cambridge University Press, Cambridge (in press)

Solomon AM (1986) Transient response of forests to $\mathrm{CO}_{2}^{-}$ induced climate change: simulation modeling experiments in eastern North America. Oecologia 68:567-579

Spurr SH, Barnes BV (1980) Forest ecology, 3rd edn. J ohn Wiley $\&$ Sons, New York

Strimbeck GR, Vann DR, J ohnson AH (1995) Effects of Ca fertilization and acid mist on $\mathrm{Ca}$ content and cold tolerance of red spruce. In: Hom J, Birdsey R, O'Brian K (eds) Proc 1995 M eet Northern Global Change Program. USDA Forest Service Gen Tech Rep NE-214. U.S. Department of Agriculture, Forest Service, Radnor, PA, p 10-12

Swetnam TW (1993) Fire history and climate change in giant sequoia groves. Science 262:885-889

Sykes MT, Prentice IC (1996) Climate change, tree species distributions and forest dynamics: a case study in the mixed conifer/northern hardwoods zone of Northern Europe. Clim Change 34:161-177
Takemoto BK, Bytnerowicz A, Dawson PJ , M orrison CL, Temple JJ (1997) Effects of ozone on Pinus ponderosa seedlings: comparison of responses in the first and second growing seasons of exposure. Can J For Res 27:23-31

Teskey RO (1995) Synthesis and conclusions from studies of southern commercial pies. In: Fox S, Mickler RA (eds) Impact of air pollutants on southern pine forests. SpringerVerlag, New York, p 467-490

Urban DL, Harmon ME, Halpern CB (1993) Potential response of Pacific Northwestern forests to climatic change, effects of stand age and initial composition. Clim Change 23:247-266

Urban DL, Shugart HH (1989) Forest response to climatic change: a simulation study for southeastern forests. In: Smith J B, Tirpak DA (eds) The potential effects of global climate change on the United States, Appendix D: Forests. EPA-230-05-89-054. U.S. Environmental Protection Agency, Washington, DC (Chapter 3)

Valentine HT, Gregoire TG, Burkhart HE, Hollinger DY (1997) Projections of growth of loblolly pine stands under elevated temperatures and carbon dioxide. In: Mickler RA, Fox S (eds) The productivity and sustainability of southern forest ecosystems in a changing environment. Ecological Studies, Vol 128. Springer-Verlag, New York, p 341-352

VEMAP Members (1995) Vegetation/ecosystem modeling and analysis project: comparing biogeography and biogeochemistry models in a continental-scale study of terrestrial ecosystem responses to climate change and $\mathrm{CO}_{2}$ doubling. Global Biogeochem Cycles 9(4):407-437

Walker LC (1991) The Southern forest: a chronicle. University of Texas Press, Austin

Williams M (1989) American and their forests: a historical geography. Cambridge University Press, Cambridge

Wilson CA, Mitchell J FB (1987) A doubled $\mathrm{CO}_{2}$ climate sensitivity experiment with a global climate model including a simple ocean. J Geophys Res 92(D11):13315-13343

Zabinski C, Davis MB (1989) Hard times ahead for Great Lakes forests: a climate threshold model predicts responses to $\mathrm{CO}_{2}$-induced climate change. In: Smith J B, Tirpak DA (eds) The potential effects of global climate change on the United States, Appendix D: Forests. EPA230-05-89-054. U.S. Environmental Protection Agency, Washington, DC (Chapter 5) 